\title{
Adulto e lúdico: atuação do profissional de Educação Física no lazer
}

\author{
Cathia Alves ${ }^{13}$ \\ Nelson Carvalho Marcellino 23 \\ ${ }^{1}$ Curso de Educação Física da UNIARARAS, Araras, SP, Brasil \\ ${ }^{2}$ Curso de Educação Física da Unimep, Piracicaba, SP, Brasil \\ ${ }^{3}$ GPL-Grupo de Pesquisa em Lazer da Unimep, Piracicaba, SP, Brasil
}

\begin{abstract}
Resumo: Este estudo teve por objetivo detectar as relações que se dão entre o adulto e o lúdico no lazer, verificando qual o papel do profissional de Educação Física como mediador entre esses elementos. A pesquisa bibliográfica ocorreu por intermédio das analises textual, temática e interpretativa. A pesquisa de campo deu-se na cidade de Americana-SP, por meio de estudo comparativo, envolvendo profissionais e adultos dentro de clubes e em um espaço público. A técnica de coleta de dados utilizada foi a observação participante, com o uso de diário de campo e formulários. O estudo detectou que os adultos encontram no tempo de lazer um caminho para suprir a necessidade que sentem da manifestação do lúdico. A atuação dos profissionais com os adultos ainda é deficiente. Constatou-se a necessidade de uma política pública de lazer para uma participação expressiva da população nessa fase da vida e que esteja fundamentada no componente lúdico da cultura.
\end{abstract}

Palavras-chave: Atividades de lazer. Adulto. Lúdico. Educação Física.

\section{The adult person and the ludic experience: the Physical Education professional's performance in the field of leisure}

\begin{abstract}
This study aimed at finding the relations that occur between the adult and the ludic experience, checking out the role of the Physical Education professional as a mediator between these elements. The literature research was conducted by means of text, thematic, and interpretative analyses. The field research was performed in the city of Americana-SP, by means of a comparative study, involving professionals and adults inside clubs, and other adults in a public space. Data collection was conducted through participant observation, using field journal and forms. The study found out that for adults the leisure field is a way to fulfill their need for the manifestation of the ludic experience. Regarding the professional's performance with adults, it is still defective. We found that there is a need for public policies of leisure, based in the ludic component of culture, for a significant participation of people in this period of life.
\end{abstract}

Key Words: Leisure activities. The adult. The ludic experience. Physical Education.

\section{Introdução}

Notando a escassez de bibliografia relativa à atuação do profissional de Educação Física com a pessoa adulta e a pouca produção teórica existente sobre a relação desse grupo com o lúdico no tempo e espaço de lazer, este artigo tem por objetivo contribuir para ampliar esse tema de estudos e fornecer subsídios para os profissionais que atuam na área em sua intermediação com essa faixa etária.

O estudo foi realizado combinando as pesquisas bibliográfica e de campo. Teve por objetivo detectar se atualmente a pessoa adulta vivencia momentos lúdicos, tendo o lazer como espaço privilegiado para a manifestação desse elemento da cultura. Procurou também verificar qual é o papel do profissional de Educação Física como mediador entre o adulto e a expressão da ludicidade.
No decorrer da pesquisa bibliográfica, pouco se encontrou sobre a relação do ser humano de idade adulta com o componente lúdico da cultura, já que este está historicamente associado à faixa etária infantil em virtude de suas representações serem, muitas vezes, limitadas aos jogos, brinquedos e brincadeiras, atividades cujo conteúdo é considerado próprio da criança (PERROTTI, 1982; OLIVEIRA, 1986; $\underline{\text { ALVES, }}$ 2007).

Dessa forma, a pesquisa de campo procurou identificar quais são as representações do lúdico para o adulto, em seu tempo e espaço de lazer, além de investigar o papel do profissional de Educação Física nesse campo.

\section{Métodos}

A pesquisa bibliográfica deu-se por intermédio das palavras-chave: lazer, adulto, lúdico e profissional de Educação Física. Realizaram-se 
as análises textuais, temáticas e interpretativas (SEVERINO, 2002). Os dados foram coletados em livros e periódicos do sistema de bibliotecas da Unimep (Piracicaba, SP) e da Unicamp (Campinas, SP).

Para pesquisa de campo, foi escolhida a cidade de Americana, SP, por amostra não probabilística (BRUYNE; HERMAN; SCHOUTHEETE, 1977) e tendo como critérios de representatividade sua taxa de urbanização $(99,8 \%)$ e de alfabetização (96\%). O Índice de Desenvolvimento Humano do Município (IDHM) é de 0,84 , ocupando a $19^{a}$ posição na classificação estadual e a $5^{a}$ na Região Metropolitana de Campinas (RMC), à qual pertence, uma vez que o lazer é uma problemática urbana (IBGE) ${ }^{1}$. Outro critério adotado foi o da acessibilidade, em virtude de um dos pesquisadores ser morador da cidade e ter autorização para acesso aos equipamentos.

A coleta da pesquisa foi realizada em clubes recreativos da cidade e em um ginásio público, todos escolhidos pelos mesmos critérios. A representatividade baseou-se em: (1) espaços nos quais são oferecidas atividades físicoesportivas de lazer dirigidas ao público adulto, com mediação de profissionais; (2) o número de associados; (3) a dimensão estrutural de cada clube e (4) a importância histórica dessas instituições na cidade. A acessibilidade aos clubes com sedes próximas ao centro da cidade também foi considerada.

Os profissionais que atuam nos clubes foram selecionados de acordo com a atividade que intermedeiam, estratificados por gênero, profissão e tempo de exercício profissional.

Como modo de investigação utilizou-se o estudo comparativo (BRUYNE; HERMAN; SCHOUTHEETE, 1977) nos clubes e no ginásio público. Foram selecionadas as nove atividades mais procuradas pelo público adulto e que contam, em sua maioria, com a intervenção do profissional de Educação Física: (1) futebol de campo masculino, (2) futebol de campo feminino, (3) bocha, (4) peteca, (5) dança de salão, (6) ginástica feminina, (7) ginástica mista, (8) musculação e (9) vôlei misto.

Para Bruyne; Herman e Schoutheete (1977) devem-se empregar várias técnicas de coletas de dados numa mesma pesquisa, de modo a reunir um conjunto de dados ao mesmo tempo disponíveis e acessíveis, conforme seu objeto de

\footnotetext{
${ }^{1}$ Informações retiradas do site: www.americana.sp.gov.br. Acesso em: 20/05/2009.
}

estudo. $\mathrm{Na}$ pesquisa de campo foram empregadas duas técnicas de coleta de dados: a observação participante e o formulário. A principal técnica de coleta de dados foi a observação participante, que pressupõe observação direta, convívio com o grupo observado e utilização de diário de campo.

O número de participantes foi fixado pela "saturação de dados". Em relação ao sexo, a pesquisa procurou, de forma não intencional, atingir um número equilibrado de homens e mulheres; por isso a escolha por atividades que envolvessem as especificidades dos dois sexos. Foram ouvidos 58 participantes, sendo 31 homens e 27 mulheres, com idades entre 20 e 60 anos. Seis profissionais participaram do estudo, sendo selecionados de acordo com a atividade que intermediavam.

\section{Resultados \\ A pesquisa bibliográfica}

Não é fácil identificar em que momento uma pessoa se torna adulta; dessa forma, encontrouse que, para o IBGE (Instituto Brasileiro de Geografia e Estatística), ser adulto significa estar entre 20 e 59 anos de idade ${ }^{2}$. Segundo Parker (1978), essa condição engloba a faixa de idade dos 20 aos 65 anos.

Optou-se por não delimitar uma faixa de idade exclusiva para o grupo de pessoas adultas, pois adulto seria aquele que assume novas responsabilidades e consegue, em alguns momentos, identificar sentido e significação em suas ações e essencialmente tem obrigações a cumprir. Em sua grande maioria, os adultos são responsáveis pelo sustento próprio e/ou da família e são vistos pela sociedade como pessoas produtivas no tempo de trabalho. São, ainda, os mantenedores da relação de produção e consumo do sistema econômico instaurado em nossa sociedade.

Neste estudo compreende-se a ordem capitalista como:

[...] um sistema social, econômico, político, cultural, ou seja, ele tem uma lógica que atua 24 horas por dia em todas as esferas da vida humana em sociedade. [...] todas as dimensões do tempo são permeadas, pelo menos nos últimos dois séculos, pela racionalidade capitalista (PADILHA, 2004, p.72)

Dessa forma, refletir sobre o lazer do adulto é apontar para a necessidade de se contextualizar

${ }^{2}$ Informação retirada do site: www.ibge.com.br. Acesso em: 21/11/2006.

Motriz, Rio Claro, v.16, n.1, p.103-112, jan./mar. 2010 
as possibilidades dessa manifestação ante as diferentes esferas de obrigação humana; significa pensá-lo não unilateralmente, mas em integração com as dimensões da família, da religião, da política e, principalmente, do trabalho, uma vez que este é um dos compromissos mais presentes na vida de um sujeito dessa faixa etária (ALVES; MARCELLINO, 2008).

O trabalho não pode se opor ao lazer, pois quando isso acontece seu propósito se reduz à dominação corporal: um não compensa o outro. É necessário usufruir dos dois campos, mantendo, assim, uma relação de complementaridade (MARCELLINO, 2002).

Geralmente, as possibilidades de vivência do componente lúdico da cultura na vida adulta são restritas. Um dos motivos diz respeito à lógica do sistema capitalista, que afasta o adulto do lúdico por valorizar exacerbadamente a produção no tempo de trabalho. Um segundo motivo fundamental verificado é a falta de educação para e pelo lazer, pois essa pesquisa detectou que a falta de tempo não é o principal motivo desse afastamento, mas, sim, não saber o que fazer durante um tempo disponível (ALVES, 2007).

Percebeu-se que as barreiras inter e intraclasses de acesso ao lazer, já discutidas por Marcellino (2002), são elementos que também cooperam para o distanciamento da pessoa adulta do lúdico. O autor indica três barreiras principais: (1) a falta de educação para e pelo lazer; (2) a situação socioeconômica e, (3) a idade.

Marcellino (2002) aponta para o processo de limitação da criança, que é instigada e direcionada a se preparar para um futuro desconhecido. E, com relação à situação do idoso, são lançadas demasiadas expectativas sobre a aposentadoria, que acaba redundando em frustrações, pois é uma fase na qual o poder financeiro do indivíduo muitas vezes diminui e sua saúde, por vezes fragilizada, também pode impedir o pleno usufruto do lazer.

Acrescenta-se que a idade adulta também é prejudicada por representar uma fase de crescente obrigação e produtividade.

A vida adulta é uma fase que está associada, principalmente, a obrigações e, em especial, ao trabalho produtivo. Conforme Elias e Dunning (1992), o trabalho é compreendido em um nível superior, como dever moral e fim em si mesmo, enquanto o lazer classifica-se em um nível inferior, como forma de preguiça e indulgência. Essa visão hierarquiza as atividades vividas pelos adultos, apontando o lazer como mero acessório do trabalho e dificultando mais as possibilidades de acesso a essa dimensão da cultura (ALVES; ISAYAMA, 2006).

O sistema capitalista pode anular as outras dimensões de expressão das pessoas por enxergar o trabalho como principal ocupação. Em alguns casos, o lazer só é valorizado quando suas atividades estão voltadas para o entretenimento no viés do consumo.

Segundo essa lógica, a vida é vista em partes, como se fosse dividida em etapas, e a faixa etária adulta é a da produção no tempo de trabalho. O adulto passa a existir como sinônimo de trabalho e as outras dimensões de sua vida, tão importantes quanto essa, ficam em segundo plano.

Muitas vezes o enfoque dado ao lazer ocorre sempre num tempo futuro, numa diversão sem memória, e baseia-se na ideia de viver emoções passageiras e imediatistas, envolvendo, inclusive, consumidores de diferentes faixas etárias (PINTO, 2001).

O lazer acaba sendo entendido como atividade de tempo livre não séria, vazia e só é valorizado quando se torna um conteúdo da moda ou um programa com altos custos, orientado pela organização da produção e consumo. Não que o lazer, dentre suas múltiplas condições, não possa incluir o consumo, porém as pessoas devem ter opções e, para isso, precisam conhecer quais são suas possibilidades.

A pesquisa bibliográfica também contribuiu para identificar alguns pontos em relação ao adulto e o lúdico. O primeiro é a pouca produção bibliográfica ligando esses dois elementos. Por outro lado, identificou-se que o componente lúdico da cultura está configurado, principalmente, nas atividades de jogo, de brincadeira e na posse de um brinquedo, elementos sempre direcionados às crianças (ALVES, 2007).

A partir dessa perspectiva, Oliveira (1986) defende que o adulto, diferentemente da criança, encara o brincar como fuga da realidade, que é marcada pelas obrigações e pela rotina. $\mathrm{O}$ autor argumenta que existe uma distância entre o adulto e o componente lúdico, e que isto se dá 
não somente pelas obrigações próprias da faixa etária, mas essencialmente pela lógica do sistema, que por ter uma visão extremamente utilitarista, classifica o tempo com valor monetário e não valoriza o lazer como tempo livre.

Por sua vez, Alves (1987) discute que a lógica do brincar vai na contramão da lógica do sistema em que o adulto está inserido, pois determina que a produção e o rendimento são mais justificáveis que qualquer outra esfera de atuação humana. $O$ autor apresenta uma visão pessimista em relação à idade adulta e coloca o jogo como uma possibilidade de "libertação" dessa lógica.

Nesse sentido, o jogo, como um dos conteúdos históricos da área da Educação Física, configura-se como uma das possibilidades de "libertação". E o profissional dessa área, como animador sociocultural, junto com outros profissionais, pode contribuir nessa tarefa se fizer esforços para recuperar o lúdico na vida do adulto.

Essa mediação não pode ocorrer de forma isolada, mas associada às demais esferas de atuação humana, inclusive a do trabalho, com a qual o adulto mantém estreita relação. Dessa forma, a animação sociocultural conectada à Educação Física, como alternativa operacional de atuação no campo do lazer, pode fazer muita diferença. Além disso, no que se refere às atividades físico-esportivas, elas mobilizam um grande número de pessoas, e a área da Educação Física que estuda o ser humano em movimento pode encontrar no lazer um espaço e um tempo para a relação entre o adulto e o lúdico.

A intervenção da Educação Física é ampla e muito importante desde que o profissional reconheça os diferentes tipos de corpos e atue a partir da intencionalidade dos movimentos, contando, também, com o diálogo entre diferentes profissionais, que dominam outros conteúdos culturais, ou áreas de relação com o lazer (ALVES, 2007); desde que, também, o lúdico seja compreendido como componente da cultura, historicamente situada, que não se manifesta de forma isolada em um único tipo de atividade, mas tem no lazer um espaço privilegiado (MARCELLINO, 2004).

Ainda entendendo o jogo como expressão do lúdico, Huizinga (1986) aponta que ele é uma atividade livre, capaz de absorver o jogador como um todo. O jogo como elemento da cultura, representado no lúdico, é algo facilmente "descartável" na faixa etária adulta, pois o autor afirma que:

Para o indivíduo adulto e responsável, o jogo é uma função que facilmente poderia ser dispensada, é algo supérfluo. Só se torna uma necessidade urgente na medida em que o prazer por ele provocado o transforma numa necessidade. É possível, em qualquer momento, adiar ou suspender o jogo. Jamais é imposto pela necessidade física ou pelo dever moral, e nunca constitui uma tarefa, sendo sempre praticado nas "horas de ócio". Liga-se a noções de obrigação e dever apenas quando constitui uma função cultural reconhecida, como no culto e no ritual (HUIZINGA, 1986, p.10-11).

Como pode o jogo ser "descartável" para o adulto sendo ele, segundo o próprio Huizinga, a base da cultura? A construção da cultura não é algo exclusivo das crianças; os adultos também constroem cultura e necessitam de prazer, claro que não só os prazeres dos jogos e brincadeiras, mas esses também são essenciais, assim como outras necessidades. O jogo não é uma tarefa, podendo, sim, ser praticado no espaço do lazer; não é obrigação nem dever, mas uma necessidade de se obter mais prazer. Se Huizinga (1986) faz essa relação no século passado, o que diria do componente lúdico para a faixa etária adulta nos dias de hoje?

Para além de Huizinga (1986), Pinto (2004) apresenta a alegria e a liberdade como alicerces para a construção da experiência lúdica. Ela afirma que esses componentes traduzem todo um processo de humanização cidadã, ou seja, por meio do lúdico as pessoas se humanizam e transcendem, podendo alcançar a cidadania.

Valoriza-se a possibilidade de vivências lúdicas na vida adulta para além do jogo, do brinquedo e da brincadeira: em todas as vivências culturais de lazer que as pessoas possam desfrutar, como teatro, cinema, um encontro com amigos, uma festa, andar de patins, cozinhar, dançar, ouvir boa música, praticar esportes, enfim, ter a opção de escolher uma atividade em um momento especial que gere prazer e alegria.

A expressão do lúdico não se manifesta somente no tempo de lazer, mas pode ser desfrutada em qualquer momento e local. No espaço do lazer, porém, sua manifestação se dá de forma privilegiada na sociedade atual.

Nessa perspectiva, o lazer é entendido como manifestação humana, com a característica básica de ocorrer num tempo/espaço disponível 
com uma atitude que envolve escolha, gratuidade e prazer. Envolve vivências como busca de superação e é um possível canal de mudança para uma realidade mais justa, em vista do desenvolvimento pessoal e social que pode propiciar.

Reitera-se a importância do "resgate" do lúdico (se é que está perdido) na vida adulta pela manifestação da ludicidade em outras esferas que não somente as do brinquedo, da brincadeira, do jogo, etc., caracterizadas como atividades de crianças.

No lazer existe a possibilidade do encontro com o prazer, um retorno às lembranças da infância e a valorização do ser criança, não de uma perspectiva conteudista, saudosista, infantilizada e "romântica", mas como processo de vida, de valorização do ser aqui e agora, como alicerce para construções futuras.

\section{Discussão \\ A pesquisa de campo}

$\mathrm{Na}$ pesquisa de campo utilizou-se, como principal técnica de coleta de dados, a observação participante com diário de campo. Posteriormente, aplicaram-se formulários aos adultos e aos profissionais. Esta seção traz a descrição tanto da observação como da discussão realizada a partir das respostas dos formulários.

A movimentação dos adultos e dos profissionais foi observada durante seis semanas, nos dias das atividades. A partir da sétima semana foram aplicados os formulários a 58 pessoas, sendo 31 homens e 27 mulheres, participantes de oito atividades físico-esportivas em quatro clubes e em uma atividade em um único espaço público da cidade. As atividades selecionadas foram: (1) futebol de campo masculino, (2) futebol de campo feminino, (3) bocha, (4) peteca, (5) dança de salão, (6) ginástica feminina, (7) ginástica mista, (8) musculação e (9) vôlei misto.

Em virtude das limitações de espaço para a escrita, optou-se por descrever a observação participante, a partir do diário de campo, em apenas quatro das nove atividades, sendo uma de cada clube e do espaço público. O critério de escolha foi o do maior número de participantes nas atividades: (1) futebol de campo masculino; (2) dança de salão de casal; (3) musculação mista e (4) vôlei misto.
No caso do futebol de campo masculino, observou-se que é possível perceber o jogo como uma representação do lúdico por meio do sorriso de muitos adultos, quando jogam, torcem ou vibram por uma boa jogada. Notou-se que eles encaram o jogo como uma chance de evasão: extravasam, xingam, gritam... A relação do profissional com os participantes é positiva, mas distante, pois ele não desenvolve uma ação efetiva de animador, como proposto na literatura específica; ele representa o papel de um árbitro de jogo.

Para Isayama (2002) a atuação do animador no campo do lazer é muito importante, pois facilita o acesso a seus interesses, possibilitando maior desenvolvimento pessoal e social como uma de suas bases. E pelo fato de o lazer abarcar uma grande diversidade cultural e estar relacionado a outros aspectos da vida social, ele exige do animador cuidado e atenção. O profissional precisa ter conhecimento e respeitar as diferenças, além de refletir e ampliar sua visão de sociedade.

Os participantes dessa atividade não demonstram sentir tanta necessidade de orientação profissional no ato do jogo por acreditarem que a atividade não visa ao rendimento. Dessa forma, verificou-se que ainda existe a ideia de que o profissional de Educação Física atua somente como um treinador, no viés da eficácia do movimento. As pessoas não o veem como um animador e mediador entre o participante e o jogo descompromissado.

$\mathrm{Na}$ dança de salão, observou-se que o profissional tem uma ação muito didática. Ele ajuda os alunos a entenderem as várias etapas de um único passo, explica de forma pausada, fala da letra e da melodia das músicas, estimulando os alunos a refletir. Com as outras aulas, detectou-se que ele é animador: dá vigor e energia ao grupo, convida os alunos a opinarem sobre os movimentos corporais durante a aula, promovendo uma visão mais crítica. Aproxima-se dos alunos, realiza os movimentos junto com eles e corrige aluno por aluno; lança perguntas, e os participantes refletem para responder.

Pode-se dizer que este profissional utiliza a animação como uma ferramenta educativa, demonstra buscar a superação do divertimento vazio e avançar com o significado de lazer, 
reforçando a importância do processo de animação sociocultural (ALVES, 2007).

Em relação aos participantes, pouco se socializam. Chegam ao salão e já fazem a posição inicial de aula. Concentram-se nos passos e poucos falam. Não costumam fazer comentários entre uma explicação e outra. Observou-se que a maioria dos casais sente-se envergonhada e tímida. Sentem-se pouco à vontade no início das aulas, mas, depois que aprendem o movimento, ficam mais "soltos" e mais à vontade.

A expressão do lúdico dá-se por meio dos movimentos da dança. Às vezes, entre um erro e outro, o professor brinca, todos riem, mas rapidamente voltam e se concentram nos passos. São silenciosos e há pouca interação entre os casais; encaram a dança com seriedade, não de forma sisuda, mas também com aspectos de brincadeira. Notou-se nessa atividade, um momento de lazer que busca alcançar os níveis crítico e criativo; os participantes se envolvem não somente pelo fato de acompanharem a esposa ou marido, mas para aprender a viver melhor por meio da dança. E o profissional é um animador sociocultural que diverte as pessoas, por meio do processo pedagógico, incentivando e dando ao grupo a oportunidade de refletir sobre o movimento da dança, é um profissional que constrói valores.

Já na musculação, o número e o sexo dos participantes variam bastante, bem como a faixa etária (dos 20 aos 60 anos). A ação do professor se dá pela montagem e orientação dos exercícios. Ele não é visto como um animador, mas como um treinador. A ação dos adultos é mais solitária e o objetivo de cada um é específico e direcionado.

Nessa atividade as relações entre os participantes não são tão perceptíveis; não há muita comunicação, a não ser entre professor e aluno, que se dá de forma tranquila e amigável. O profissional interage muito bem com os alunos: orienta, conversa e é muito atencioso. A musculação é uma atividade procurada para manutenção da saúde, e os participantes não encaram essa atividade como um tempo de lazer. Por isso esperam que o profissional seja um treinador e não um animador.

Para uma mudança nesse quadro é necessário pensar em duas frentes de atuação: (1) o profissional precisa entender que além de treinador ele é um animador, que interage com as pessoas no tempo de lazer; (2) as pessoas precisam rever o conceito de lazer, entendendo que esse tempo não é somente de diversão e descanso, mas também propicia o desenvolvimento da saúde. $E$ nesse sentido o papel do profissional é imprescindível, educando para e pelo lazer.

No vôlei misto não há intervenção de um profissional. De todos os grupos escolhidos, esse foi o que mais nos chamou a atenção, pois representa a adesão ao lúdico como componente da cultura, que pratica o esporte pelo simples prazer que proporciona. É nítida a manifestação do elemento lúdico nesse ambiente. É perceptível também a forma diferenciada com que os adultos encaram o jogo e a competição; é um grupo autônomo e alegre.

Percebeu-se facilmente o tempo de lazer com a fruição do lúdico, por meio da prática desinteressada, num tempo livre e com uma atividade satisfatória. Todos conversam e fazem brincadeiras e não há qualquer tipo de preconceito ou resistência.

O grupo é animado e estimulado para a prática; um animador inserido nesse espaço teria a possibilidade de reconhecer junto ao grupo os problemas e limites da realidade, podendo enfrentá-los diante de expressões da cultura, nesse caso, o esporte. O grupo demonstrou que não busca um profissional porque não deseja um treinador/técnico.

Dessa forma, a atuação do profissional no lazer deve se dar no sentido de contradição, em busca de modificações pelo caminho da animação. É preciso esforço para estruturar todo um contexto em que as pessoas possam se encontrar, questionar, participar e ser ativas.

Em relação à idade dos participantes, deixouse em "aberto"; não se fez uma classificação específica de adultos mais jovens e ou mais maduros. As faixas de idade estavam bem distribuídas e a predominante foi a dos 20 aos 30 anos.

Quanto à aplicação dos formulários aos adultos, selecionaram-se três fatores mais pertinentes a essa temática: (1) como se dá a escolha das atividades; (2) a ligação entre o lúdico e o lazer; e (3) a relação que se estabelece com o profissional. 
Em relação à escolha das atividades, notou-se pela fala das participantes que o predominante é o gosto pela ação, a preocupação com a saúde e o corpo e, em poucos casos, a proximidade do clube. Os homens destacaram que buscam as atividades para estabelecer relações de amizade, prevalecendo o interesse social.

Perguntou-se aos participantes quais as atividades que mais praticavam dentro dos clubes. Identificou-se que eles procuram variedade, geralmente participando de uma a duas atividades.

Percebeu-se, também, que para cada atividade foi apresentada uma justificativa diferente, de acordo com suas especificidades, identificando o tipo de modalidade e o objetivo que cada praticante procura. Por exemplo, os alunos da musculação estavam preocupados com a saúde e o bem-estar físico. Já os motivos que atraíram praticantes do futebol e da peteca são mais parecidos, pois buscavam aproximação com os amigos.

$\mathrm{Na}$ escolha das atividades prevaleceu a procura por relações humanas, encontros para criar vínculos afetivos e de amizade e para aprofundar relações.

Quanto à relação entre o lúdico e o lazer, as atividades, em sua grande maioria, são entendidas pelos participantes como lazer (aspectos do tempo e atitude), e a presença do componente lúdico foi constante, representado por palavras como: amizade, liberdade, coisa gostosa, alívio, distração, bem-estar, qualidade de vida, prazer, disposição, relaxamento e divertimento. Definir o que é o lúdico é desenhar essas sensações. Detectou-se que essas palavras também revelam o significado que 0 lazer tem para essas pessoas.

Verificou-se que vários participantes sentem falta do componente lúdico e afirmam não saber como resolver isso. Outros não conseguem perceber que quando viajam, praticam esportes e/ou dançam encontram-se com o lúdico no lazer, como espaço privilegiado. Não conseguem detectar esse fato pela visão restrita que ainda têm sobre o lazer e o componente lúdico. As pessoas também afirmaram que o trabalho e as demais obrigações tomam muito tempo.

Percebeu-se que poucos participantes não sentem falta da vivência lúdica, porque suprem essa necessidade por meio de vivências no campo do lazer, ou pelo prazer que têm no trabalho, e por outras vivências permeadas por características lúdicas. Alguns adultos, porém, ainda indicam os finais de semana como possibilidade de felicidade e solução dos problemas.

Segundo Marcellino (2005), os finais de semana são canais de possibilidades, mas o sentido da vida não pode ser buscado apenas por esse caminho. $O$ adulto deve considerar as possibilidades de lazer nos fins de semana e no final do expediente, contanto que saiba que existem outras condições para essa vivência e tenha consciência do lazer como cultura vivenciada no tempo disponível.

Detectou-se que a maior parte dos participantes tem lembranças de manifestações do lúdico durante a infância. Os adultos sentem falta dessas manifestações, ou seja, sentem saudade da infância (ALVES, 2003). Ainda que, por vezes, a infância não tenha sido tão "boa", o ser humano tem a tendência a preservar o que foi bom e a lembrar-se disso; daí o desejo de voltar ao que foi bom. Isso não quer dizer que a vida de adulto também não possa ser "boa".

Quanto à atuação dos profissionais, os adultos confirmaram, em seus discursos, a importância de sua intermediação. Porém, não os veem como animadores. Na maioria das situações eles são vistos como treinadores: é o caso da ginástica e do futebol.

$\mathrm{Na}$ bocha e no vôlei não há a intervenção profissional e também não se percebeu a necessidade dela (segundo os discursos dos participantes, que afirmaram que essa atividade não exige um profissional); nesse caso, o local poderia trabalhar com animadores profissionais de competência geral. Dentro do processo de animação eles teriam outras preocupações e metas junto ao grupo, como a participação de voluntários para atuarem no dia-a-dia do clube.

Já na peteca, os participantes gostariam que houvesse a intermediação do profissional, por vários motivos: o principal é a preocupação em abrir uma turma de base e para divulgação do esporte. Na dança de salão os adultos afirmaram que a presença do profissional é essencial.

É importante destacar que a atuação do profissional no campo do lazer, como um 
animador, visa, acima de tudo, desafiar os indivíduos a alterações reais em suas vidas. Pela adesão a atividades próprias, procurará promover mudanças estruturais como única forma de realizar uma autêntica ideologia da transformação social e do desenvolvimento (CARVALHO, 1977). Nesse sentido, o lazer pode confirmar ainda mais seu caráter educativo.

Muitos dos praticantes apontaram a necessidade de um "animador" e não de um treinador esportivo. Eles buscam um profissional que intermedeie a ação sem cobrar esforço físico e eficácia na execução dos movimentos; um profissional que anime, organize, dialogue e incentive as práticas corporais.

Assim, é preciso alertar para a ideia que as pessoas têm do profissional do lazer, entendendo que sua presença só é importante nos momentos de produtividade, desvalorizando o lazer como divertimento e brincadeira e depreciando também o profissional que anima esse momento.

Foram ouvidos seis profissionais que atuam diretamente nessas atividades. Todos eles trabalham com lazer há mais de cinco anos. Foram destacados três itens fundamentais para esse estudo: (1) a formação dos profissionais; (2) a preferência por atuar com faixas etárias diferenciadas; e (3) a relação com o público adulto.

Quanto à formação, dois dos seis profissionais não têm nível superior e apenas um tem pósgraduação em Educação Física. Um dos profissionais que não têm formação em Educação Física fez curso especializado na área de dança, que é seu campo de atuação; o outro profissional não tem formação superior.

É necessário destacar a importância da competência específica, o compromisso político e a reflexão sobre os rumos da ação de cada profissional (MARCELLINO, 2003). A formação é fundamental para uma atuação eficaz; é uma ferramenta de base para a competência. Através dela é possível transformar a ideia limitada que as pessoas têm do lazer como simples divertimento e alcançar uma consciência crítica, tanto do profissional como do participante e assim caminhar para a reflexão.

Os profissionais não apresentaram preferência por trabalhar com uma idade específica. De certa forma, isso é positivo, pois o profissional acaba tendo uma maior flexibilidade e um leque maior de opções; ao mesmo tempo, porém, ele pode não dar conta de atender às necessidades específicas de cada grupo, que tem características e exigências diferenciadas.

Segundo Carvalho (1977), a função da animação seria: (1) proporcionar maior compreensão das pessoas em relação ao mundo que as cerca; (2) maior compreensão da sociedade em que o indivíduo se encontra; (3) uma preparação mais extensa diante das mudanças de comportamento da sociedade e de tudo que a cerca. Assim, o profissional que se especializa em um tipo de grupo tem a possibilidade de levá-lo à compreensão do mundo, das pessoas e das mudanças que acontecem nesse meio.

Os profissionais explicitaram os valores da relação com o público adulto, mostrando que aspectos como respeito, qualidade de vida, consciência corporal, descontração, ética e amizade precisam ser considerados na atuação com essa faixa de idade. Quando indagados sobre as dificuldades de atuar com adultos, informaram que nem sempre eles querem participar das atividades. Mencionaram, também, a questão da dificuldade na execução dos movimentos, nas práticas corporais, o que, segundo eles, é uma limitação.

Nota-se que os profissionais ainda precisam se aprofundar sobre a intenção dos movimentos dos corpos adultos e entender seu papel como animadores.

Dessa forma, a atuação do animador no campo do lazer facilitaria o acesso a seus interesses, possibilitando maior desenvolvimento pessoal e social como uma de suas bases (ISAYAMA, 2002). A execução do movimento correto não pode ser a principal preocupação do animador sociocultural nas atividades de lazer, mesmo que a atividade seja de caráter físicoesportivo.

A questão do lazer ainda é vista de forma isolada tanto pelos profissionais como pelos participantes. Portanto, é preciso um plano de ação no sentido da educação para e pelo lazer de todos os caminhos possíveis de educação cultural.

\section{Considerações Finais}

Estabelecem-se, assim, três parâmetros norteadores entre o lúdico e o adulto.

1. Considera-se que o adulto sente falta do componente lúdico e busca, por meio do lazer, 
sanar essa ausência; e os que não sentem essa falta têm no tempo de lazer a solução para essa manifestação.

2. A falta do componente lúdico na vida adulta também é verificada pela distância que existe entre os adultos e as crianças. Em alguns momentos, essa falta se dá pelo não engajamento dos participantes nas atividades.

3. O lúdico, para o adulto, é a manifestação de liberdade, alegria, movimento, relaxamento, pausa. É sonhar e criar expectativas, é jogar e brincar, é superação, é vitória e derrota. É elevarse e ir além do esperado na tentativa de ultrapassar barreiras; é divertir-se e distrair-se, é mudar para outra parte e desviar-se. Desviar-se em busca de um momento melhor do que aquele que passou. Os adultos buscam no tempo de lazer o encontro com o lúdico, que durante o cotidiano pode se manifestar timidamente em virtude das preocupações com as obrigações e compromissos.

Confirma-se, pelo estudo, tanto na revisão bibliográfica como na pesquisa de campo, que o adulto vivencia momentos lúdicos por meio do lazer. E, portanto, o lazer é hoje um espaço privilegiado para a manifestação do lúdico na sociedade. Aliás, é possível dizer que em nossa sociedade o lazer é um dos poucos espaços para que isso ocorra.

Quanto à intermediação do profissional entre o adulto e o lúdico, é importante reiterar três constatações:

1. o profissional de educação física como animador sociocultural é visto de maneira superficial, porque as pessoas não o reconhecem como tal, já que desconhecem esse tipo de ação;

2. ele é visto como um treinador/preparador físico; essa visão domina o entendimento dos participantes. Isso pode se dar pelo fato de que as pessoas buscam no tempo de lazer momentos associados à prática de uma atividade física para a melhoria da saúde física e para a manutenção da aparência, ainda que a maior parte dos homens tenha afirmado procurar amigos. De maneira geral, os adultos não conhecem a atuação de um animador sociocultural no tempo de lazer;

3. a formação dos profissionais de Educação Física para atuação no lazer não é vista com grande importância, uma vez que, na seleção de conteúdos dos currículos, o "lazer" é percebido como algo menor (com poucas disciplinas e, muitas vezes, uma somente). Muitos profissionais não se veem como animadores, assim como o público também não os enxerga dessa forma. Alguns não fazem de sua atuação uma prática política e pedagógica: política no sentido de dar autonomia e capacitar os participantes com uma visão crítica e criativa; e pedagógica no sentido de que não transformam seu conteúdo e não o ajustam de acordo com a necessidade dos participantes.

O campo do lazer, como espaço privilegiado para a manifestação lúdica, pode ser espaço de exercício para a cidadania, uma vez que, a partir do divertimento e do desenvolvimento pessoal, pode ocorrer a transformação do indivíduo em pessoa, e no desenvolvimento social, a transformação da pessoa em cidadão.

Conclui-se, portanto, que o lúdico, entendido como componente da cultura, é importante na vida do adulto. Ainda que em nossa sociedade as relações da pessoa adulta com o lúdico e o lazer sejam moldadas pelos valores da produção e consumo e o lúdico seja visto com preconceitos que limitam suas representações, é necessário que haja uma ação democratizante que combata e lute pela superação dessas barreiras.

Considera-se que o lúdico associado à animação sociocultural é um canal de contribuição para a superação do conformismo e vivência de lazer vazio e o profissional de educação física é ponto essencial para essa superação e para a busca de significado.

Portanto, relacionar educação física e animação sociocultural, como base na ligação do adulto com o lazer, considerado espaço privilegiado para manifestação do lúdico, é compreender uma das necessidades dessa fase de vida e buscar a construção de uma nova sociedade.

Destacam-se alguns pontos que contribuem para a atual situação do lazer das pessoas de faixa etária adulta: (1) a falta de educação para e pelo lazer, por meio de expressões dos meios de comunicação de massa, via ideologia vigente; (2) a falta de preparo dos adultos para desfrutarem seu tempo livre, associando o lazer a experiências individuais isoladas, o que supõe visões parciais e reduz seu amplo conceito; (3) o uso do lazer, por parte do sistema, como instrumento de conformismo e compensação.

O profissional de educação física, como mediador entre a cultura enquanto patrimônio da humanidade e a ação dos adultos, precisa buscar, em sua esfera de atuação profissional, a superação dos níveis de lazer conformistas, com valores funcionalistas, para níveis críticos e criativos. Mas não bastam ações individuais; são necessárias políticas de ação articuladas que 
envolvam órgãos públicos, profissionais e população interessada.

\section{Referências}

ALVES, C; ISAYAMA, H. F. Considerações sobre o lazer na idade adulta. In: MARCELLINO, Nelson Carvalho. Repertorio de atividades por fases da vida. Campinas: Papirus, 2006.

ALVES, C. O papel do profissional de Educação Física como intermediário entre o adulto e o lúdico. 2007. 150 f. Dissertação (Mestrado) - Faculdade de Ciências da saúde. Curso de Educação Física, Unimep.

ALVES, C; MARCELLINO, N. C. O profissional de Educação Física como animador sociocultural atuando nos clubes da cidade de Americana-SP: contribuições nas relações entre o Lazer e a Idade Adulta. Licere, Belo Horizonte, UFMG, vol. 11, n. 01, 2008.

ALVES, R. A gestação do futuro. Campinas: Papirus, 1987.

Quando eu era menino. Campinas:

Papirus, 2003.

BRUYNE, P; HERMAN, J; SCHOUTHEETE, M. Dinâmica da pesquisa em ciências sociais. Rio de Janeiro: Francisco Alves, 1977.

CARVALHO, A. M. Cultura física e

desenvolvimento. Lisboa: Compedium, 1977.

ELIAS, N; DUNNING, E. A busca da excitação. Lisboa: Difel, 1992.

HUIZINGA, J. Homo ludens: o jogo como elemento da cultura. São Paulo: Perspectiva/EDUSP, 1986.

IBGE: banco de dados da cidade de Americana. Disponível em: <www.ibge.com.br>. Acesso em: 20/05/2009.

IBGE: banco de dados. Disponível em: <www.ibge.com.br>. Acesso em: 21/11/2006.

ISAYAMA, H. F. Recreação e lazer como integrantes de currículos dos cursos de graduação em educação física. 2002. (Tese de Doutorado) - Departamento de Educação Física, Universidade de Campinas, Campinas.

MARCELLINO, N. C. Estudos do lazer uma introdução. 3. ed. Campinas: Autores Associados, 2002.

(org.) Formação e desenvolvimento de pessoal em lazer e esporte. Campinas: Papirus, 2003.
Lazer e educação. 11. ed. Campinas:

Papirus, 2004.

Pedagogia da animação. 7. ed.

Campinas: Papirus, 2005.

OLIVEIRA, P; S. Brinquedo e indústria cultural. Petrópolis: Vozes, 1986.

PADILHA, V. Apontamentos para um estudo crítico sobre políticas públicas de lazer. Licere. Belo Horizonte, v. 7, n. 1, 2004.

PARKER, S. A sociologia do lazer. Rio de Janeiro: Zahar, 1978.

PERROTTI, E. A criança e a produção cultural. In: ZILBERMAN, R. (Org.). A produção cultural para a criança. Porto Alegre: Mercado Aberto, 1982.

PINTO, L. M. M. Formação de educadores e educadoras para o lazer: saberes e competências. Revista Brasileira de Ciências do Esporte, v. 22, n. 3, mai. 2001.

Educação física, corporeidade, lazer: diálogos com amigos sobre "riscos a correr". In: MOREIRA, Wagner W. (Org). Educação física intervenção e conhecimento científico. Piracicaba: Unimep, 2004.

SEVERINO, A. J. Metodologia do trabalho científico. São Paulo: Cortez, 2002.

Esse estudo é parte da Dissertação de Mestrado, que tem como título: $O$ papel do profissional de Educação Física como intermediário entre o adulto e o lúdico. Defendida em 02/2007, pela linha de pesquisa em Corporeidade e Lazer, na Unimep, sob orientação do professor Nelson Carvalho Marcellino.

Endereço:

Cathia Alves

Rua São Gonçalo, 152 Jd. N. Sra. do Carmo

Americana SP Brasil

13.472-290

e-mail: cathiaal@hotmail.com

Recebido em: 29 de julho de 2009. Aceito em: 10 de dezembro de 2009.

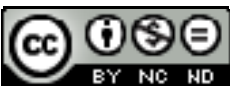

Motriz. Revista de Educação Física. UNESP, Rio Claro, SP, Brasil - elSSN: 1980-6574 - está licenciada sob Licenca Creative Commons 